
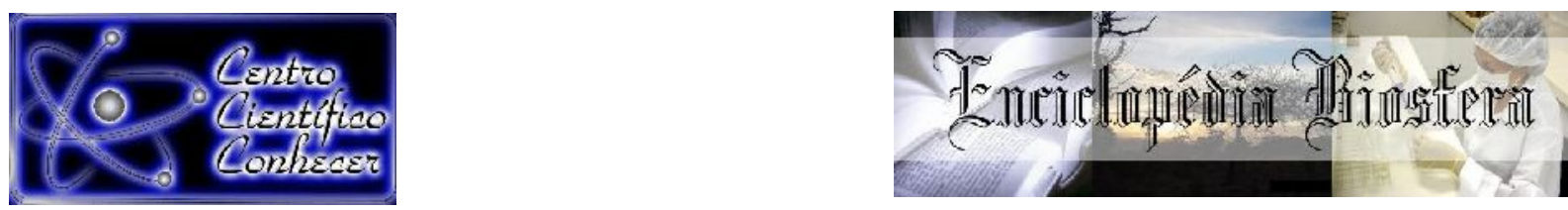

\title{
INOCULAÇÃO FOLIAR DE PLANTAS DE MILHO COM Bacillus subtilis e Azospirillum brasilense
}

\author{
Raphael Willian Bego Machado ${ }^{1}$, Vinicius de Oliveira Calvi ${ }^{2}$, Edneia Aparecida de Souza \\ Paccola ${ }^{3}$, Edison Schmdit Filho ${ }^{4}$, Francielli Gasparotto ${ }^{4}$ \\ ${ }^{1}$ Acadêmico do curso de graduação em Agronomia da Universidade Cesumar (Unicesumar), \\ Maringá - PR, Brasil. \\ ${ }^{2}$ Acadêmico do curso de graduação em Agronomia da Universidade Cesumar (Unicesumar), \\ Maringá - PR, Brasil. \\ ${ }^{3} \operatorname{Prof}^{\mathrm{a}} \mathrm{Dr}^{\mathrm{a}}$ do Programa de Mestrado em Tecnologias Limpas e do Departamento de Agronomia \\ da Universidade Cesumar (Unicesumar), Maringá - PR, Brasil. Pesquisadora do Instituto \\ Cesumar de Ciência, Tecnologia e Inovação (ICETI). \\ ${ }^{4}$ Prof. Dr. do Programa de Mestrado em Tecnologias Limpas e do Departamento de Agronomia \\ da Universidade Cesumar (Unicesumar), Maringá - PR, Brasil. Pesquisador do Instituto \\ Cesumar de Ciência, Tecnologia e Inovação (ICETI). \\ ${ }^{5} \operatorname{Prof}^{\mathrm{a}} \mathrm{Dr}^{\mathrm{a}}$ do Programa de Mestrado em Tecnologias Limpas e do Departamento de Agronomia \\ da Universidade Cesumar (Unicesumar), Maringá - PR, Brasil. Pesquisadora do Instituto \\ Cesumar de Ciência, Tecnologia e Inovação (ICETI) - (francielli.gasparotto@unicesumar.edu.br)
}

\section{Recebido em: 15/11/2020 - Aprovado em: 15/12/2020 - Publicado em: 30/12/2020 DOI: 10.18677/EnciBio_2020D22}

A redução do emprego de adubos minerais e da poluição ambiental durante a produção agrícola é uma necessidade crescente, assim como o aprimoramento das técnicas de cultivo de milho, gramínea de grande importância social e ambiental. Para tal, estudos que acarretem aumento de produtividade com redução de custos de produção e impactos ao meio ambiente se fazem essenciais. Deste modo, objetivou-se avaliar a inoculação de plantas de milho do híbrido FS512PW com Azospirillum brasilense e Bacillus subtilis via foliar, visando atenuar a dependência da produção aos fertilizantes químicos e auxiliando na sustentabilidade agrícola regional. Foram avaliados os seguintes tratamentos: T1 - Testemunha; T2 $-50 \mathrm{~kg} \mathrm{ha}^{-1}$ de $\mathrm{N}$ em cobertura; T3 Azospirillum brasilense via foliar; T4 - Aplicação de Bacillus subtilis via foliar; T5 Azospirillum brasilense e Bacillus subtilis via foliar. Os parâmetros avaliados foram: altura de plantas; produtividade de grãos; massa de mil grãos e o retorno econômico. A aplicação de Bacillus subtilis via foliar proporcionou significativamente o aumento da altura e da produtividade das plantas de milho e maior retorno econômico em relação aos demais tratamentos analisados. Enquanto a aplicação desta bactéria associada a Azospirillum brasilense não acarretou benefícios em relação a testemunha, assim como a inoculação com Azospirillum brasilense. Assim, conclui-se que o uso de Bacillus subtilis é uma alternativa rentável ao produtor rural e pode ser utilizado como uma alternativa na busca pela sustentabilidade dos sistemas produtivos de milho.

PALAVRAS-CHAVE: diazotróficos, sustentabilidade, Zea mays. 


\title{
FOLIAR INOCULATION OF CORN PLANTS WITH Bacillus subtilis and Azospirillum brasilense
}

\begin{abstract}
Reducing the use of mineral fertilizers and environmental pollution during agricultural production is a growing need, as is the improvement of techniques for growing corn, a grass of great social and environmental importance. To this end, studies that lead to increased productivity with reduced production costs and impacts on the environment are essential. In this way, the objective was to evaluate the inoculation of corn plants of the hybrid FS512PW with Azospirillum brasilense and Bacillus subtilis via leaf, aiming to reduce the dependence of production on chemical fertilizers and aiding in the regional agricultural sustainability. The following treatments were evaluated: T1 - Witness; T2 $50 \mathrm{~kg} . \mathrm{ha}^{1}$ of $\mathrm{N}$ in coverage; T3 -Azospirillum brasilense via leaf; T4 - Application of Bacillus subtilis via leaf; T5 - Azospirillum brasilense and Bacillus subtilis via leaf. The evaluated parameters were: plant height; grain yield; thousand grain mass and economic return. The application of Bacillus subtilis via leaf provided a significant increase in the height and productivity of corn plants and greater economic return in relation to the other treatments analyzed. While the application of this bacterium associated with Azospirillum brasilense did not bring benefits in relation to the control, as well as the inoculation with Azospirillum brasilense. Thus, it is concluded that the use of Bacillus subtilis is a profitable alternative to rural producers and can be used as an alternative in the search for the sustainability of maize production systems.
\end{abstract}

KEYWORDS: diazotrophic, sustainability, Zea mays.

\section{INTRODUÇÃO}

O milho (Zea mays L.) é cultivado em diversas regiões brasileiras e apresenta relevante importância social e econômica, sendo utilizado na alimentação humana e animal, constituindo uma das principais comodities do agronegócio brasileiro. Estima-se que na safra 2019/20 sua produção superará os 102 milhões de toneladas, considerando as três safras que podem ser realizadas no território brasileiro, alcançará a marca de 18,5 milhões de hectares cultivados com esta gramínea e uma produtividade média de $5.533 \mathrm{~kg} \cdot \mathrm{ha}^{-1}$ (CONAB, 2020).

Paralelo a este aumento produtivo ocorreu também a elevação do consumo de fertilizantes, principalmente dos nitrogenados, já que o nitrogênio $(\mathrm{N})$ é o principal nutriente extraído pelas plantas de milho e sua extração aumenta linearmente com o aumento da produtividade da cultura (COELHO, 2006). Assim, o uso intenso e o custo dos fertilizantes vêm elevando os custos de produção do milho, chegando a este item representar $18,44 \%$ do custo total da cultura. Uma alternativa para diminuir o emprego dos fertilizantes nitrogenados é o uso de microrganismos que realizam a fixação biológica deste (CARMO et al., 2020).

As bactérias fixadoras de nitrogênio podem fixar nitrogênio atmosférico e o disponibilizar para as plantas, reduzindo assim o uso de fertilizantes nitrogenados (REIS et al., 2020). Dentre essas bactérias destacam-se as do gênero Azospirillum, grupo que vem tendo seu efeito no desenvolvimento e produção da cultura do milho estudado já alguns anos (HUNGRIA et al., 2010; ANDRADE et al., 2019). Azospirillum 
representa o gênero mais bem caracterizado de rizobactérias promotoras de crescimento de plantas e sua utilização está relacionada com o aumento de assimilação de nitrogênio e na atividade de enzimas fotossintéticas nas plantas por ela colonizadas (CASSÁN; DIAZ-ZORITA, 2016). Ainda segundo os autores a inoculação do milho com Azospirillum brasilense, provoca aumento na matéria seca de raízes, aumentando o desenvolvimento da planta.

Além de Azospirillum brasilense, outro grupo de bactérias que vem tendo sua aplicação na cultura de milho avaliada é o gênero Bacillus (PAIVA et al., 2020). A associação microrganismos deste grupo com as plantas de milho acarretam diversas vantagens, pois estes produzem antibióticos, fitohormônios e enzimas, proporcionando a promoção do crescimento das plantas e o controle biológico de fitopatógenos (BUCHELT et al., 2019).

Assim, estudos que visem avaliar a interação de bactérias fixadoras de nitrogênio e diferentes cultivares de milho em diferentes regiões produtoras brasileiras se fazem necessários, a fim de otimizar o processo produtivo atenuando a dependência aos fertilizantes nitrogenados e auxiliando na sustentabilidade. Desta forma, objetivou-se avaliar a inoculação de plantas de milho do híbrido FS512PW com Azospirillum brasilense e Bacillus subtilis via foliar.

\section{MATERIAL E MÉTODOS}

O experimento foi realizado no município de Doutor Camargo, região noroeste do

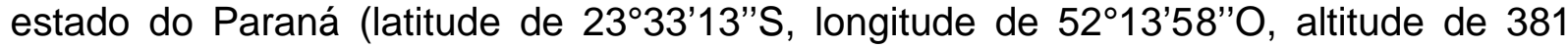
metros). O solo da área experimental foi classificado como um Latossolo Vermelho eutrófico com textura argilosa (SANTOS et al., 2018).

O clima da região é caracterizado como subtropical, tendo média anual de $22^{\circ} \mathrm{C}$; e semi-úmido, com média de $1.590 \mathrm{~mm}$ anuais de chuva, as temperaturas mais baixas são entre os meses de maio a julho, enquanto as temperaturas mais altas são entre novembro a março (NITSCHE et al., 2019).

O delineamento experimental utilizado foi o de blocos casualizados, com 5 tratamentos e 4 repetições, totalizando 20 parcelas. Cada parcela foi constituída por 6 linhas de 10 metros com espaçamento entre linhas de 0,45 metros, ou seja, $27 \mathrm{~m}^{2}$, sendo a colheita realizada somente nas linhas centrais totalizando $8,1 \mathrm{~m}^{2}$. Os tratamentos foram: T1- adubação na base; T2 - Adubação na base + aplicação de Bacillus subtilis via foliar; T3 - Adubação na base + aplicação de Azospirillum brasilense via foliar; T4 - Adubação de base + aplicação de Azospirillum brasilense e Bacillus subtilis via foliar e T5 - Adubação de base com + 50 kg.ha ${ }^{-1}$ de $\mathrm{N}$ em cobertura.

A semeadura foi realizada com semeadora de arrasto no sistema plantio direto, com uma densidade de 2,7 sementes por metro linear e população de 60000 plantas por hectare, sendo utilizado o híbrido FS512PW. A adubação de base empregada em todos os tratamentos foi realizada com o formulado $10-15-15$ na dose de $250 \mathrm{~kg}$.ha ${ }^{-1}$.

As aplicações de nitrogênio em cobertura e a inoculação via foliar com Azospirillum brasilense e Bacillus subtilis foram realizadas quando as plantas apresentaram entre quatro $(\mathrm{V}-4)$ e seis $(\mathrm{V}-6)$ folhas com bainhas formadas, aproximadamente entre 40 a $60 \mathrm{~cm}$ de altura. Utilizou-se inoculante líquido a base de Azospirillum brasilense $\left(1 \times 10^{11} \mathrm{UFC} / \mathrm{L}\right)$ na dose de $300 \mathrm{ml}^{-h^{-1}}$ e inoculante liquido a 
base de Bacillus subtilis (550 g/L) na dose de $300 \mathrm{ml}^{-h^{-1}}$, de acordo com a recomendação técnica dos fabricantes. As aplicações foram realizadas com pulverizador costal manual na área total das parcelas de acordo com os tratamentos. Já o T5, consistiu na adubação em cobertura com uréia, de forma manual em área total de acordo com a dose estabelecida no referido tratamento.

A colheita foi realizada manualmente no estádio $R 6$, no qual todos os grãos da espiga já tinham alcançado o máximo peso seco e vigor e as espigas foram debulhadas com uma trilhadeira acoplada a tomada de potência do trator. As variáveis analisadas foram:

- Altura de plantas (AP): foi feito a medição com uma trena milimétrica o comprimento da planta, desde a superfície do solo até a extremidade do pendão (em metros);

- Produtividade de grãos $(P)$ : para avaliação da produtividade em cada tratamento, foram colhidas duas linhas centrais de cada parcela; as espigas foram debulhadas com o auxílio de uma trilhadeira. Após a colheita de cada parcela o milho foi pesado e mensurado sua umidade, peso de mil grãos (PMS), sendo os dados expressos em kg.ha-1.

- Retorno econômico (R): Para análise financeira considerou-se o custo da adubação em cobertura e da inoculação, o valor da saca de milho de $60 \mathrm{~kg}$ no mercado nacional cotado no dia 21/10/2020 em 73,00, a produtividade da área e a lucratividade obtida em moeda monetária nacional $(R \$)$. Sendo 233,00 reais por hectare o custo da ureia utilizada na adubação de base e cobertura, 84,00 para a aplicação de Azospirillum brasilense, $R \$ 30,00$ para a aplicação de Bacillus subtilis e $\mathrm{R} \$ 114,00$ para aplicação das duas bactérias em conjunto.

Com base nos resultados de produção por tratamento e nos valores do custo de produção realizou-se o cálculo do retorno econômico $(\mathrm{R})$ de acordo com a Equação 1 adaptada de Donato e Bonato (2013).

$$
R=((\text { Ptrat }- \text { Ptest }) X M)-C
$$

Em que:

Ptrat $=$ produtividade de cada tratamento com aplicação de inoculante ou adubo em cobertura, sc.ha' ${ }^{-1}$;

Ptest $=$ produtividade da testemunha sem cobertura, sc.ha ${ }^{-1}$;

$\mathrm{M}=$ preço da saca do milho; e

$\mathrm{C}=$ custo de cada tratamento.

Os dados obtidos foram submetidos ao teste $\mathrm{F}$, nível de $5 \%$ de probabilidade. Quando significativo às médias foram comparadas pelo Teste Scott-Knott, também ao nível de $5 \%$ de probabilidade. As análises de variância foram realizadas com o auxílio do programa estatístico SISVAR ${ }^{\circledR}$.

\section{RESULTADOS E DISCUSSÃO}

Dentre os parâmetros avaliados a altura média de plantas apresentou diferença significativa, sendo que os tratamentos ficaram distribuídos em três grupos, plantas com 
maior altura ocorreram no tratamento com aplicação de Bacillus subtilis (T2) de forma isolada e com menor altura no tratamento que recebeu $50 \mathrm{~kg} \cdot \mathrm{ha}^{-1} \mathrm{de} \mathrm{N} \mathrm{em} \mathrm{cobertura}$ (T5). Os demais tratamentos apresentaram valores intermediários (Tabela 1).

Este aumento significativo da altura de plantas possivelmente está relacionado a diferentes atividades realizadas por Bacillus subtilis, como a solubilização de nutrientes, a produção de fitohormônios e metabólitos de ação fungicida e bactericida (HASHEM et al., 2019). E ainda, outros efeitos benéficos para a cultura estão associados a síntese de ácido indolacético (AIA), solubilização de fósforo, zinco e produção de sideróforos por estes organismos (MUMTAZ et al., 2017).

Corroborando estes resultados, Ferreira et al. (2018) também verificaram incrementos na altura e na tolerância a salinidade em plantas de milho derivados da inoculação de Bacillus subtilis e Lima et al. (2011) observaram que Bacillus subtilis potencializou o efeito do fertilizante nitrogenado na cultura do milho. Ressalta-se que nesta pesquisa a inoculação foi realizada via foliar, e da mesma forma observou-se benefícios no crescimento das plantas de milho.

TABELA 1. Valores médios de altura, produtividade (PROD) e peso de mil grãos (PMG) de milho submetidos a adubação com diferentes fontes de nitrogênio.

\begin{tabular}{cccc}
\hline TRATAMENTO $^{1}$ & $\begin{array}{c}\text { ALTURA } \\
\text { (cm) }\end{array}$ & $\begin{array}{c}\text { PROD } \\
\text { (kg.ha- }^{-1}\end{array}$ & $\begin{array}{c}\text { PMG } \\
\text { (g) }\end{array}$ \\
\hline T1 & $2,64 \mathrm{ab}$ & $8880 \mathrm{~b}$ & $385 \mathrm{a}$ \\
T2 & $279 \mathrm{a}$ & $9720 \mathrm{a}$ & $382 \mathrm{a}$ \\
T3 & $2,64 \mathrm{ab}$ & $9000 \mathrm{~b}$ & $373 \mathrm{a}$ \\
T4 & $2,61 \mathrm{ab}$ & $8700 \mathrm{~b}$ & $377 \mathrm{a}$ \\
T5 & $2,54 \mathrm{~b}$ & $8880 \mathrm{~b}$ & $379 \mathrm{a}$ \\
\hline
\end{tabular}

1Tratamentos: T1_250kg.ha-1 do formulado 10-15-15; T2-250kg.ha-1 do formulado 10-15-15 + Bacillus subtilis via foliar; T3-250kg.ha" ${ }^{-1}$ do formulado 10-15-15+ Azospirillum brasilense via foliar; T4-250kg.ha-1 do formulado 10-15-15 + Azospirillum brasilense + Bacillus subtilis via foliar; T5-250kg.ha-1 do formulado 10-15-15 + 50kg.ha ${ }^{-1}$ de $\mathrm{N}$ em cobertura.

Médias seguidas de letras iguais, nas colunas, não diferem estaticamente pelo teste Tukey $(p<0,05)$.

Quanto a produtividade verificou-se também que a inoculação com Bacillus subtilis propiciou um aumento significativo na produtividade da cultura em relação aos demais tratamentos, com aumento de $1020 \mathrm{~kg}$ em relação ao tratamento com pior desempenho (T4) e 0,840 kg para a testemunha (T1). Destaca-se que os demais tratamentos não diferiram da testemunha, inclusive o tratamento que recebeu aplicação foliar de Bacillus em conjunto com Azospirillum.

Alguns autores alegam que o uso do gênero Azospirillum não garante que serão obtidos efeitos significativos no crescimento, produção e rendimento da cultura do milho (PANDOLFO et al., 2014; VASCONCELOS et al., 2016). O que tem sido priorizado é a utilização destes organismos para aumentar a eficiência diazotrófica, otimizar o uso dos fertilizantes nitrogenados e promover melhor aproveitamento dos nutrientes do solo.

Considerando que a rizobactéria Azospirillum brasilense, em função de estabelecer uma relação apenas associativa com o milho, dificilmente disponibilizará ao mesmo a quantidade de nitrogênio necessária para atender a demanda da planta por ENCICLOPÉDIA BIOSFERA, Centro Científico Conhecer - Jandaia-GO, v.17 n.34; p. 293 2020 
este elemento, recomenda-se que o microrganismo não seja aplicado isoladamente, mas sim combinado com o fertilizante nitrogenado em cobertura (HUNGRIA et al., 2010).

Kappes et al. (2017) e Santini et al. (2018) também não verificaram respostas para crescimento e acúmulo de nitrogênio em plantas de milho em função da inoculação via foliar desta bactéria. Provavelmente porque estas são mais eficientes em colonizar o sistema radicular do que a parte aérea das plantas, a indução de efeitos a partir de outra estrutura vegetal pode representar gastos energéticos para seu estabelecimento o que contribui para minimizar a produção de respostas de crescimento para as plantas (CASSÁN; DIAZ-ZORITA, 2016)

Porém, ao realizar a análise do retorno econômico de cada um dos tratamentos em relação a testemunha (T1) (Tabela 2), observou-se que a aplicação via foliar das espécies bacterianas Bacillus subtilis ou Azospirillum brasilense contribuíram significativamente para o aumento do retorno econômico da atividade para o produtor. Principalmente, a inoculação com Bacillus subtilis de forma isolada (T2), que proporcionou um aumento de lucratividade para o produtor em $11,17 \%$, considerando o custo de aplicação de 30,00 reais por hectare, e resultou em um retorno econômico por hectare para o produtor de $R \$ 992,00$ reais a mais do que a testemunha.

TABELA 2. Retorno econômico da cultura de milho submetida a diferentes fontes de nitrogênio em cobertura.

\begin{tabular}{cccc}
\hline Tratamentos $^{1}$ & $\begin{array}{c}\text { Custo } \\
\text { aplicação.ha } \\
\text { (R\$) }\end{array}$ & $\begin{array}{c}\text { Produtividade }^{-1} \\
\text { (sacas.ha }^{-1} \text { ) }\end{array}$ & $\begin{array}{c}\text { Retorno Econômico } \\
\text { (R\$) }\end{array}$ \\
\hline T1 & - & 148 & - \\
T2 & 30,00 & 162 & 992,00 \\
T3 & 84,00 & 150 & 62,00 \\
T4 & $30+84,00$ & 145 & $-333,00$ \\
T5 & 233,00 & 148 & $-233,00$ \\
\hline
\end{tabular}

1Tratamentos: T1 _ 250kg.ha-1 do formulado 10-15-15; T2 - 250kg.ha-1 do formulado 10-15-15 + Bacillus subtilis via foliar; T3-250kg.ha-1 do formulado 10-15-15+ Azospirillum brasilense via foliar; T4 - 250kg.ha 1 do formulado 10-15-15 + Azospirillum brasilense + Bacillus subtilis via foliar; T5 - 250kg.ha-1 do formulado $10-15-15+50 \mathrm{~kg} \cdot$ ha $^{-1}$ de N em cobertura.

${ }^{2}$ Preço da saca de milho $-\mathrm{R} \$ 73,00$

A aplicação de Azospirillum brasilense embora tenha proporcionado um aumento na lucratividade da cultura, este aumento não foi tão expressivo quanto ao uso de Bacillus subtilis, acarretando lucro de $R \$ 62,00$ reais a mais que a testemunha. Dartora et al. (2013), avaliando o desenvolvimento do milho frente à inoculação com Azospirillum brasilense, encontrou um incremento de $922 \mathrm{~kg} \mathrm{ha}^{-1}$ quando comparado com à testemunha, possibilitando um ganho de 15 sacas a mais por ha cultivado sugerindo a aplicabilidade da inoculação para o cultivo do milho, o que não ocorreu nas condições deste experimento.

Porém, observou-se que quando as duas bactérias testadas foram aplicadas em conjunto não ocorreu aumento tanto na altura das plantas quanto na produção da cultura, pelo contrário, causou uma redução da produtividade e uma diminuição no lucro 
do produtor em $\mathrm{R} \$ 333,00$ reais quando comparado com a testemunha. Este fato pode estar relacionado a uma possível competição entre as duas espécies de bactérias por exsudatos liberados pela planta, o que pode ter acarretado menor população destes organismos benéficos sobre a folha e consequentemente menor ação sobre as plantas de milho.

Bactérias antagônicas como o Bacillus subtilis, de modo geral, agem significativamente por antibiose e, ocasionalmente, por parasitismo e competição (HASHEM et al., 2019). Mediante a produção de substâncias tóxicas devido a ação de competição e antibiose, estas bactérias podem ter produzido substâncias que prejudicaram o desenvolvimento de Azospirillum brasilense, inviabilizando assim a aplicação em conjunto dos dois organismos.

Em relação a aplicação da ureia na forma de adubação de cobertura, seu retorno econômico proporcionado não justificou o custo de aplicação, de modo que foi obtido a mesma produção da testemunha que só foi realizada a adubação de base e houve uma queda no retorno econômico em $\mathrm{R} \$ 233,00$ reais por hectare. Embora este trabalho não tenha encontrado incrementos produtivos mediante a aplicação de uréia, outros autores encontraram aumento na produtividade de milho mediante adubação nitrogenada mineral com doses variando de 80 a $100 \mathrm{~kg} \mathrm{ha}^{-1}$ de $\mathrm{N}$ em cobertura (ARAÚJO et al., 2004; OLIVEIRA et al., 2009).

\section{CONCLUSÃO}

A aplicação de nitrogênio via foliar de Azospirillum brasilense e Bacillus subtilis é uma alternativa rentável ao produtor, pois tais produtos proporcionaram um aumento na rentabilidade da cultura quando empregados isoladamente.

A inoculação via foliar em conjunto de Azospirillum brasilense e Bacillus subtilis não acarretou benefícios as plantas nas condições deste experimento.

Entre os microrganismos avaliados destacou-se o uso de Bacillus subtilis que proporcionou um aumento na lucratividade do produtor em $\mathrm{R} \$ 992,00$ reais por hectare em relação a testemunha, apresentando-se como uma forma rentável de produção ao produtor rural.

A aplicação de Bacillus via foliar é sustentável ao meio ambiente, proporcionando um sistema de produção no qual explora a relação entre plantas e organismos benéficos e reduz a necessidade da adubação química.

\section{AGRADECIMENTOS}

Ao ICETI (Instituto Cesumar de Ciência, Tecnologia e Inovação) pelo apoio e concessão de bolsa de pesquisa.

\section{REFERENCIAS}

ANDRADE, A. de F.; ZOZ, T.; ZOZ, A.; OLIVEIRA, C. E. da S.; WITT, T. W. Azospirillum brasilense inoculation methods in corn and sorghum. Pesquisa Agropecuária Tropical, v.49, e53027, 2019. Disponível em: https://doi.org/10.1590/198340632019v4953027. DOI: 10.1590/1983-40632019v4953027. 
ARAÚJO, L.A.N.; FERREIRA, M.E.; CRUZ, M.C.P. Adubação nitrogenada na cultura do milho. Pesquisa Agropecuária Brasileira, v.39, n.8, p.771-777, 2004. Disponível em: https://www.scielo.br/pdf/pab/v39n8/21738.pdf.

BUCHELT, A. C.; METZLER, C. R.; CASTIGLIONI, J. L.; DASSOLLER, T. F.; LUBIAN, M. S. Aplicação de bioestimulantes e Bacillus subtilis na germinação e desenvolvimento inicial da cultura do milho. Revista de Agricultura Neotropical, v. 6, n. 4, p. 69-74, 2019. Disponível em: https://doi.org/10.32404/rean.v6i4.2762. DOI: 10.32404/rean.v6i4.2762

CARMO, K. B.; BERBERII, G. C. M.; BOURSCHEIDTIII, M. L. B.; GARCIAI, M. N.; SILVA, A. F.; FERREIRA, A. Desempenho agronômico do milho safrinha em resposta a doses de nitrogênio combinadas com inoculante biológico em Mato Grosso. Scientific Electronic Archives, v.13, n.7, p.95-101, 2020. Disponível em: http://dx.doi.org/10.36560/13720201163. DOI: 10.36560/13720201163.

CASSÁN, F.; DIAZ-ZORITA, M. Azospirillum sp. in current agriculture: From the laboratory to the field. Soil Biology and Biochemistry, v. 103, p. 117-130, 2016. Disponível em: https://doi.org/10.1016/j.soilbio.2016.08.020.

COELHO, A.M. Nutrição e adubação do milho. Sete Lagoas: EMBRAPA Milho e Sorgo. 2006. 10 p. (Circular técnica, 78). Disponível em:

https://www.infoteca.cnptia.embrapa.br/infoteca/bitstream/doc/490410/1/Circ78.pdf

CONAB - Companhia Nacional de Abastecimento. Acompanhamento da safra brasileira de grãos, v. 7 - Safra 2019/20 - Décimo segundo levantamento, Brasília, p. 1-33, 2020. Disponível em: https://www.conab.gov.br/info-agro/safras.

DARTORA, J; GUIMARÃES, V. F.; MARINI, D.; SANDER, G. Adubação nitrogenada associada à inoculação com Azospirillum brasilense e Herbaspirillum seropedicae na cultura do milho. Revista Brasileira de Engenharia Agrícola e Ambiental, v.17, n.10, p.1023-1029, 2013. Disponível em: https://doi.org/10.1590/S141543662013001000001. DOI: 10.1590/S1415-43662013001000001.

DONATO, F. V.; BONALDO, S. M. Avaliação de diferentes fungicidas no controle de doenças foliares no milho na região norte de Mato Grosso. Enciclopédia Biosfera, v. 9, n. $17 ; \quad$ p. $375-384, \quad 2013 . \quad$ Disponível em: http://www.conhecer.org.br/enciclop/2013b/CIENCIAS\%20AGRARIAS/AVALIACAO\%20 DE\%20DIFERENTES.pdf.

FERREIRA, N. C.; MAZZUCHELLI, R. DE C. L.; PACHECO, A. C.; ARAUJO, F. F. DE, ANTUNES, J. E. L.; ARAUJO, A. S. F. DE. Bacillus subtilis improves maize tolerance to salinity. Ciência Rural, v. 48, n.8, e20170910, 2018. Disponível em: https://doi.org/10.1590/0103-8478cr20170910.

HASHEM, A.; TABASSUM, B.; ABD-ALLAH, E. F. Bacillus subtilis: A plant-growth ENCICLOPÉDIA BIOSFERA, Centro Científico Conhecer - Jandaia-GO, v.17 n.34; p. 296 2020 
promoting rhizobacterium that also impacts biotic stress. Saudi Journal of Biological Sciences, v. 26, n. 6, p. 1291-1297, 2019. Disponível em: https://doi.org/10.1016/j.sjbs.2019.05.004.

HUNGRIA, M.; CAMPO, R. J.; SOUZA, E. M.; PEDROSA, F. O. Inoculation with selected strains of Azospirillum brasilense and $A$. lipoferum improves yields of maize and wheat in Brazil. Plant and Soil, v. 331, n. 1, p. 413-425, 2010. Disponível em: https://doi.org/10.1007/s11104-009-0262-0. DOI: 10.1007/s11104-009-0262-0.

KAPPES, C.; SILVA, R. G. da; FERREIRA, V. E. N. Aplicação foliar de Azospirillum brasilense e doses de nitrogênio em cobertura no milho safrinha. Scientia Agraria Paranaensis, v. 16, n. 3, p. 366-373, 2017. Disponível em: http://dx.doi.org/10.18188/1983-1471/sap.v16n3p366-373. DOI: $\quad 10.18188 / 1983-$ 1471/sap.v16n3p366-373.

LIMA, F. F.; NUNES, L. A. P. L.; FIGUEIREDO, M. do V. B.; ARAÚJO, F. F. de; LIMA, L. M.; ARAÚJO, A. S. F. de. Bacillus subtilis e adubação nitrogenada na produtividade do milho. Revista Brasileira Ciências Agrárias, v. 6, n. 4, p. 544-550, 2011. Disponível em: http://www.redalyc.org/src/inicio/ArtPdfRed.jsp?iCve=119021237016.

MUMTAZ, M. Z.; AHMAD, M.; JAMIL, M.; HUSSAIN, T. Zinc solubilizing Bacillus spp. potential candidates for biofortification in maize. Microbiological Research, v. 202, n. 1, p. 51-60, 2017. Disponível em: https://doi.org/10.1016/j.micres.2017.06.001. DOI: 10.1016/j.micres.2017.06.001.

NITSCHE, P. R.; CARAMORI, P. H.; RICCE, W. da S.; PINTO, L. F. D. Atlas Climático do Estado do Paraná. Londrina, PR: IAPAR, 2019. Disponível em: http://www.idrparana.pr.gov.br/Pagina/Atlas-Climatico.

OLIVEIRA, F.A., CAVALCANTE, L.F., SILVA, I.F., PEREIRA, W.E., OLIVEIRA, J.C., FILHO, J.F.C. Crescimento do milho adubado com nitrogênio e fósforo em um Latossolo Amarelo. Revista Brasileira de Ciências Agrárias, v.4, p.238-244, 2009. Disponível em: http://dx.doi.org/10.5039/agraria.v4i3a1. DOI: 10.5039/agraria.v4i3a1

PANDOLFO, C. A.; VOGT, G. A.; BALBINOT JUNIOR, A. A.; GALLOTTI, G. J. M.; ZOLDAN, S. R. Desempenho de milho inoculado com Azospirillum brasilense associado a doses de nitrogênio em cobertura. Agropecuária Catarinense, v. 27, n. 3, p. 94-99, 2014. Disponível em: https://publicacoes.epagri.sc.gov.br/RAC/article/view/567/471.

PAIVA, C. A. O.; MARRIEL, I. E.; GOMES, E. A.; COTA, L. V.; SANTOS, F. C. dos; et al.,; Recomendação agronômica de cepas de Bacillus subtilis (CNPMS B2084) e Bacillus megaterium (CNPMS B119) na cultura do milho. Sete Lagoas: Embrapa Milho e Sorgo, 2020. 18p. (Embrapa Milho e Sorgo. Circular Técnica, 260).

REIS, C. R. G; PACHECO, F. S.; REED, S. C.; TEJADA, G.; NARDOTO, G. B.; FORTI, 
M. C.; OMETTO, J. P. Biological nitrogen fixation across major biomes in Latin America: Patterns and global change effects. Science of The Total Environment, v.746, 140998, 2020. Disponível em: https://doi.org/10.1016/j.scitotenv.2020.140998. DOI: 10.1016/j.scitotenv.2020.140998.

SANTINI, J. M. K.; BUZETTI, S.; TEIXEIRA FILHO, M. C. M.; GALINDO, F. S.; COAGUILA, D. N.; BOLETA, E. H. M. Doses and forms of Azospirillum brasilense inoculation on maize crop. Revista Brasileira de Engenharia Agrícola e Ambiental, v. 22, n. 6, p. 373-377, 2018. Disponível em: https://doi.org/10.1590/18071929/agriambi.v22n6p373-377. DOI: 10.1590/1807-1929/agriambi.v22n6p373-377.

SANTOS, H. G. dos; JACOMINE, P. K. T.; ANJOS, L. H. C. dos; OLIVEIRA, V. A. de; LUMBRERAS, J. F.; COELHO, M. R.; ALMEIDA, J. A. de; ARAUJO FILHO, J. C. de; OLIVEIRA, J. B. de; CUNHA, T. J. F. Sistema Brasileiro de Classificação de Solos 5. ed., rev. e ampl. - Brasília, DF.: Embrapa, 2018. 356 p.: ISBN 978-85-7035-800-4. Disponível em: https://www.embrapa.br/busca-de-publicacoes//publicacao/1094003/sistema-brasileiro-de-classificacao-de-solos.

VASCONCELOS, A. C. P. de; SIQUEIRA, T. P.; LANA, R. M. Q.; FARIA, M. V. de; NUNES, A. A.; LANA, A. M. Q. Seed inoculation with Azospirillum brasilense and N fertilization of corn in the Cerrado biome. Revista Ceres, v. 63, n. 5, p. 732-740, 2016. Disponível em: https://doi.org/10.1590/0034-737x201663050019. DOI: 10.1590/0034737x201663050019. 